\title{
Perceived Effects of Computer-Based Examination (CBE) on Essay Writing Skills of Undergraduates in Ambrose Alli University, Ekpoma, Edo State
}

DOI: https://doi.org/10.47175/rielsj.v2i1.200

\author{
${ }_{1,2}$ Institute of Education \\ Ambrose Alli University, \\ Ekpoma \\ ${ }^{3}$ Faculty of Education \\ Ambrose Alli University, \\ Ekpoma \\ a.hashemi@riau.ac.ir
}

| Olusi F. I $^{1}$ | Onobun Angela ${ }^{2}$ Anolu Easter ${ }^{3}$ |

\begin{abstract}
The study examined the perceived effects of Computer-Based Examination (CBE) on essay writing skills of undergraduates in Ambrose Alli University, Ekpoma, Edo State. One research question was raised and answered while the three hypotheses were formulated and tested in the study. The descriptive research design was adopted for the study. The population of this covered all the 27,388 regular undergraduate students in Ambrose Alli University, Ekpoma. A sample size of 546 students were selected for the study. The proportional random sampling technique was used to select $2 \%$ of the total number of students across each of the faculties in the institution. The instrument used for the collection of data was developed by the researcher and titled: "Computer Based Examination Perception Questionnaire (CBEPQ)". The instrument has a reliability alpha $(\alpha)$ of 0.78 . The research question was analysed using the mean $(\bar{X})$ and standard deviation (S.D) while the $t$-test statistics for two independent samples was used to test hypothesis 1, 2 and 3 at 0.05 level of significance. Based on findings, it can be concluded that computer-based examination (CBE) has effect on their essay writing skills as undergraduates in Ambrose Alli University, Ekpoma, Edo State. Hence, it is concluded that undergraduate students of Ambrose Alli University, Ekpoma perceived that computer-based examination (CBE) has effect on their essay writing skills. Female undergraduates of Alli University, Ekpoma, Edo State had higher perception on the effect of CBE on essay writing but their perception of CBE on essay writing did not differ by age and level of study.

KEYWORDS

Computer-Based Examination (CBE); Essay Writing;

Undergraduates; Examination
\end{abstract}

\section{INTRODUCTION}

Information and Communication Technology (ICT) is an umbrella term that includes communication device or application, encompassing radio, television, cellular phones, computers, network, hardware and software, satellite systems and so on, as well as the various services and applications associated with them (Kumar, 2006). ICT focuses specifically on the application of these new technologies in an educational context and environment, and serves as a tool for supporting the various components of education. Such components include, among others, teaching and learning, resources management (human, material, financial resources) and admission and examination processes also known as learning assessment. One specific form of ICT for assessment is the Computer-Based 
Examination (CBE) which also known as Computer-Based Assessment, Computer-Based Testing or e-examination.

Computer-Based Examination (CBE) is a method of administering tests in which the responses are electronically recorded, assessed, or both. It is commonly available for several admissions tests in developed countries and more recently; in developing countries (Alabi, Issa \& Oyekunle, 2012). This method of evaluation is important because it can measure different skills or sets of knowledge in order to provide new and better information about individuals' abilities. Colleges and universities receive CBE results more quickly than those from paper-based test, and they can make their admissions decisions more quickly. Individuals can take a CBE even with minimal or no previous computer experience; since, instructions provided in a basic computer tutorial before the test will provide the experience needed to take the test using a mouse. One may spend much time on the tutorial to ensure comfortability with the computer and with the test before the official timed examination.

There are two (2) types of CBEs namely: linear and adaptive. A linear examination or test is a full-length assessment in which the computer selects different questions for individuals without considering their performance level. It consists of a full range of test questions-from easiest to most difficult-hut not always in that order. The linear test is scored in the same way as a paper-based test. On the other hand, a computer adaptive test is one in which the computer selects the range of questions based on individuals' performance level. These questions are taken from a very large pool of possible questions categorized by content and difficulty. When you take a paper-based test, you will find that you are asked to answer questions ranging from easy to hard. In a computer-based adaptive examination, each examination-candidate receives questions that are at the right level of difficulty for his or her ability. These examinations begin with a question that is of medium level of difficulty for most test takers. After each question is answered, the computer uses the answer and all previous answers to determine which question will be answered next. The next question is one that best follows the previous performance. This means that different examination sitters even in the same room on the same day will receive different questions. Since adaptive test questions are selected according to performance on previous questions, less time is spent than on a paper-based test on questions that are either too easy or too hard. Usually, one cannot skip ahead or go back as is possible with the paper-based examination.

Computer based examination of one of the technology based assessment methods that provides opportunities to measure complex form of knowledge and reasoning that is not possible to engage and assess through traditional methods (Bodmann \& Robinson, 2004). In Nigeria, employers now conduct aptitude test for job seekers through electronic means; the universities and other tertiary institutions are registering and conducting electronic examination for their students through the internet and other electronic and networking gadgets. Similarly, different examination bodies in the country such as West Africa Examination Council (WAEC), National Examinations Council (NECO), National Business and Technical Examination Board (NABTEB), and National Teachers' Institute (NTI), among others register their students through electronic means (Olawale \& Shafii, 2010).

Furthermore, computer based examination (CBE) and related technologies provide powerful tools to meet the new challenges of designing and implementing assessments methods that go beyond the conventional practices and facilitate to record a broader repertoire of cognitive skills and knowledge. Agah, Ogbeche and Okorie (2016) noted that CBE enables educators and trainers to author, schedule, deliver and report on surveys, quizzes, tests and exams. It could be a stand-alone system or a part of a virtual learning environment, possibly accessed via the World Wide Web (www). In addition to the examination itself, CBE takes care of other related activities that interact with the assessment 
such as test administration, setting questions and automated marking. Computers are used by candidates to conduct their examinations online, usually in the form of multiple choice questions, submit and get immediate results. This is opposed to paper based examinations where candidates are expected to write and expressing their thoughts in the form of an independent essay.

Essay writing is an aspect of English language that deals putting words, phrases and sentences together to express a given thoughts by writing a composition on a given title, question or article title. It requires the writer to use their initiative and creativity in expressing themselves on a given subject. CBE has been largely criticized particularly when the system is newly introduced in an educational institution and the technical issues that accompany implementation. It may also possess some long-run effect on students' essay writing skills and competencies.

Some of the effects of CBE on essay writing as identified by Durojaye and Okon (2016) include: lowering of students' morale for writing, reduction of students' mechanical accuracy, weakening their ability to build their vocabulary, comprehension skills; ability to use of punctuations such as full stop, comma, question marks; construction of loose sentences, transliteration from the mother tongue; abuse of the basic rules of grammar; wrong spellings, wrong usage of concord, poor tense usage; use capitalization of letters; wrong use of capital and small letters in a Noun; ignorance of the proper use of punctuation marks; inability of students to appropriate the use of present and past tenses; wrong expressions and poor use of parts of speech and their functions in sentences. Mubashrah, Tariq and Shami (2012) noted that one factor that has been of interest to educators is the integration of CBE in the school system is learner's acceptance and perceptions towards the method.

Perception by definition is an inner psychic state influencing behaviour. It refers to an inner state from actions and words. For instance, we may presume that a person actively avoiding a computer has a negative perception towards it. Attitude is not an inborn, instinct phenomenon; it mainly depends upon person's experience and its impact in a new situation (Saparniene, Merkys, \& Saparnis, 2002). Consequently, perception is formed in the process of experience and their change is possible due to the internal and external factors. In other words, perception towards computer based examination in this study is defined as ways of thinking and feelings of the students towards Computer Based examination (CBE). Agah, Ogbeche and Okorie (2016) noted that intrinsic or personal variables such as gender, age and study level could affect learner's perceived effects to CBE on essay writing.

Gender according to Adigun, Onihunwa, Irunokhai, Sada and Adesina (2015) is a sociological construct that refers to a wide range of biological, emotional mental, behavioural, and physical characteristics that can be attributed to "maleness" or "femaleness" of an individual. It describes the range of physical, biological, mental and behavioural characteristics pertaining to and differentiating between the feminine and masculine population. However, Adigun, et al (2015) submitted that it is often used interchangeably with the term "sex" which is the biological range of "male" and "female". Discussing the influence of gender on students' perception towards ICT, Sanni and Mohammad (2015) noted that male students often hold more value perception on computer based examination than their female counterparts. He attributed this to socio-cultural differences between girls and boys that often made people attribute some vocations and professions such as engineering, construction works, arts and crafts, among others to men while catering, typing, nursing, secretarial duties, teaching is considered a female domain.

Age refers to the length of time one has lived or existed. It is usually described in terms of number of years. It has often been regarded as the state of the mind, implying that age has 
nothing to do with years but abilities and competencies of individuals. However, the fact still remains that the capabilities, exposures and experiences of an older learner could be difference from the younger ones. Sanni and Mohammad (2015) asserted that perceptions on use and acceptance of information technology resources may vary with age of learners as a result of exposure. They argued that attitude is direct function of learner's age. That is, perceived effect of computer based examination on essay writing skills is an increasing function of age.

Level of study is one personal attribute that describes the years a student has stayed on a course of study in an academic institution. It also helps to distinguish students according to their discipline or course of study within an academic institution. For instance, a student in 500Level describes a student in Engineering, Architecture, Medical Laboratory and some other disciplines in the sciences while a student in final year student in 400level explains a student whose duration of programme takes 4years. According to Agah, Ogbeche, and Okorie (2016) Computer Based Examination (CBE) is a technology driven approach towards evaluating students. The remains that knowledge of students increases are students increases in the academic ladder of their study programme. Hence, they noted that attitude of old and graduating students could be more favourable towards CBE than their counterparts that are "freshers". To determine the influence of personal variables - sex, age, and level of study on perceived effects of computer-based examination (CBE) on essay writing skills of undergraduates in Ambrose Alli University, Ekpoma, Edo State.

The management of Ambrose Alli University, Ekpoma implemented the use of CBE in the 2016/2017 academic session. The advantages of using computer technology for educational assessment have been recognised by numerous staff to include: lowered administrative cost, time saving and less demand upon lecturers among others. Whilst recognising these system-level advantages, it has been observed that some examination candidates experience some challenges such as difficulties with navigating backwards to rework problems. Some are resistant to the computerized process because they are accustomed to taking notes and circling questions and/or answers for later review. Some students say that they read more quickly and more easily on paper than on a glaring computer screen. While electronic glitches are rare, they have been known to occur, for instance where computer crashes can void the efforts of large numbers of test takers. All these conflicting positions serve may affect reactions, acceptance and attitude towards the assessment system.

Studies on attitude towards CBE have attracted the attention of scholars in recent times. In Ilorin, attitude of undergraduate students towards computer-based examination (CBE) in Ilorin, Nigeria was carried out by Adeyinka and Bashorun (2012) who found that generally, respondents had positive attitude towards $\mathrm{CBT}$ as more than average of the respondents preferred CBT to paper and pencil test. Sam and Aduwa-Ogiegbaen (2008) carried out a study on attitude towards Computer Assisted Instruction in universities in Southern Nigeria and found that students had negative attitude towards Cai. However, little is known about the attitude of secondary school students towards Computer-Based Training (CBT). Therefore, it is pertinent to examine the attitude of secondary school students towards Computer-Based Training (CBT) in Nigeria. In Nsukka Enugu State, Agah, Ogbeche and Okorie (2016) investigated computer anxiety, operation skills and attitude as correlates of students' preparedness for computer based assessment. The result has shown that computer anxiety, operation skill and attitude are good predictors of students' preparedness for computer-based-assessment in Enugu.

In spite of what is known on the attitude of undergraduate students towards ComputerBased examination (CBE) in Nigeria. It is not to the researcher's knowledge that any study has been carried out among undergraduates on this area of interest in Edo State. Hence, a 
knowledge gap exists. To fill this gap, it has become pertinent to determine perceived effects of computer-based examination (CBE) on essay writing skills of undergraduates in Ambrose Alli University, Ekpoma, Edo State

\section{RESEARCH METHODS}

The descriptive research design using the survey was adopted in this study to examine attitude towards computer based examination (CBE) among undergraduates of Ambrose Alli University, Ekpoma, Edo State. This research design was employed because the variables of study were not be manipulated and opinions of a representative sample were sought and presented in their natural setting to draw inferences. The population of this covered all the 27,388 regular undergraduate students in Ambrose Alli University, Ekpoma in the 2019/2020 academic session. A sample size of 546 students was selected for the study. The proportional random sampling technique was used to select $2 \%$ of the total number of students across each of the faculties in the institution. The proportionate random was used in other to drawn a sample from a homogenous group or stratum (which represents faculties in this study).

The instrument used for the collection of data was developed by the researcher and titled: "Computer Based Examination Perception Questionnaire (CBEPQ)". The questionnaire (CBEPQ) was divided into two Sections of Section A and B. Section A contains questions bio-data of the respondent (students) such as the name of their department, sex, age and level of study while the Section B contains 16 items covering: perceived effect of CBE on essay writing (items 1-16). All the items were rated on a four point rating scale: Strongly Agreed (SA)_4, Agreed (A)_3, Disagreed (D)_2 and Strongly Disagreed (SD)_1. A mean score of 2.50 was used as the criterion mean for the questionnaire. This was obtained by adding up the four point responses (e.g Strongly Agreed -4, Agreed -3, Disagreed -2 and Strongly Disagreed -1) and dividing the sum of the scales (10) by the total number of scales (4) to give 2.50 . Hence, any item with a score of 2.50 or higher would be adjudged as agreed upon while any item with a score of 1 to 2.49 were taken otherwise. The respondents are expected to choose one of the options that best suit their opinions on the items in the questionnaire.

The face and content validity of this instrument (CBEAQ) was carried out by the project supervisor and two other experts in the Department of Guidance and Counselling in Ambrose Alli University, Ekpoma. A draft of the questionnaire was given to them to read through and make corrections. Their corrections and suggestions were integrated into the final copy of the questionnaire. This was done to ensure that items on the questionnaire are clear, precise and unambiguous. The test-retest method was used to determine the reliability of the instrument. This method was used to obtain responses from a total of twenty (20) part-time undergraduate students in the Emaudo annex of Ambrose Alli University, Ekpoma. The instrument were administered to them and re-administered after a few days to the same set of students in a pilot study. Their responses from the first and second pre-test administration were analyzed using the Pearson Product Moment Correlation (PPMC) technique and a reliability coefficient of 0.78 was obtained which shows the instrument is reliable. The researcher personally administered the questionnaires to students with the assistance of departmental executives (excos) in various faculties of the institution. Few minutes was given to volunteers to fill to questionnaire after which the instrument was collected immediately. This was to ensure that a sufficient amount of time was given to fill them and to enhance the return rate.

Research question 1 was analysed using mean $(\overline{\mathrm{X}})$ and standard deviation (S.D). A mean score of 2.50 was used as the benchmark for determining students' attitude on the item statements. This was obtained by adding up the four point responses (e.g Strongly Agreed - 
4, Agreed -3, Disagreed -2 and Strongly Disagreed -1) and dividing the sum of the scales (10) by the total number of scales (4) to give 2.50. Hence, a score of 2.50 or higher represents positive attitude while means score of 1 to 2.49 was taken otherwise. The t-test statistics for two independent samples was used to test hypothesis 1, 2 and 3. All the hypotheses were tested at 0.05 level of significance using the Statistical Package for Social Science (SPSS $®$ 23).

\section{RESULTS AND DISCUSSION}

This section deals with the presentation of result and discussion of results.

Hypothesis 1: This hypothesis states that there is no significant difference between male and female undergraduate on the perceived effects of computer-based examination (CBE) on essay writing skills of undergraduates in Ambrose Alli University, Ekpoma, Edo State

Table 1. T-test Analysis on undergraduate Perceived effects of Computer-Based Examination (CBE) on essay writing skills according to gender

\begin{tabular}{|l|l|l|c|l|l|l|l|}
\hline Variables & Sex & $\mathbf{N}=546$ & $\overline{\mathbf{X}}$ & S.D & t-cal. & p-value & Remark \\
\hline $\begin{array}{l}\text { Students' } \\
\begin{array}{l}\text { Attitude } \\
\text { towards CBE }\end{array}\end{array}$ & Male & 242 & 2.51 & .436 & & & $\begin{array}{l}\text { Reject null } \\
\text { hypothesis } \\
\text { (p<0.05) }\end{array}$ \\
\cline { 2 - 5 }
\end{tabular}

* t-calculated value is significant at 0.05 level of significance

Result in Table 3 showed that the calculated t-value of -2.444 is statistically significant $(\mathrm{p}<0.05)$. Therefore, the null hypothesis is rejected. This means that there is a significant difference between male and female undergraduate on the perceived effects of computerbased examination (CBE) on essay writing skills of undergraduates in Ambrose Alli University, Ekpoma, Edo State. This further implies that undergraduate students' perception on the effects of computer-based examination (CBE) on essay writing skills differed by sex. Furthermore, the result showed that their perception mean score of male undergraduates $(\mathrm{N}=242, \overline{\mathrm{X}}=2.51)$ was less than that of female undergraduates $(\mathrm{N}=294, \overline{\mathrm{X}}=2.60)$.

Hypothesis 2: This hypothesis states that there is no significant difference between young and old undergraduate on the perceived effects of computer-based examination (CBE) on essay writing skills of undergraduates in Ambrose Alli University, Ekpoma, Edo State

Table 2. Analysis of Perceived effects of Computer-Based Examination (CBE) on Essay Writing skills of Undergraduates in Ambrose Alli University, Ekpoma, Edo State according to age

\begin{tabular}{|c|c|c|c|c|c|c|c|}
\hline Variables & Age & $\mathbf{N}=546$ & $\overline{\mathbf{X}}$ & S.D & t-cal. & p-value & Remark \\
\hline \multirow{2}{*}{$\begin{array}{l}\text { Students' } \\
\text { Attitude } \\
\text { towards CBE }\end{array}$} & Young students & 312 & 2.55 & .439 & \multirow[b]{2}{*}{-.708} & \multirow[b]{2}{*}{0.479} & \multirow{2}{*}{$\begin{array}{l}\text { Null hypo- } \\
\text { thesis retained } \\
(p>0.05)\end{array}$} \\
\hline & Old students & 224 & 2.58 & .422 & & & \\
\hline
\end{tabular}

* t-calculated value is significant at 0.05 level of significance

Result in Table 4 showed that the calculated t-value of -.708 for students' attitude towards Computer-Based examination (CBE) is not statistically significant ( $p>0.05)$. Therefore, the null hypothesis is retained. This means that there is a significant difference between young and old undergraduate on the perceived effects of computer-based examination (CBE) on essay writing skills of undergraduates in Ambrose Alli University, Ekpoma, Edo State. This further implies that perceived effects of computer-based examination (CBE) on essay writing skills of undergraduates in Ambrose Alli University, 
Ekpoma, Edo State differed by age. This is because the perceived means effect score of young undergraduates $(\mathrm{N}=312, \overline{\mathrm{X}}=2.55)$ was slightly less than that of old undergraduates $(\mathrm{N}=224, \overline{\mathrm{X}}=2.58)$ but not significantly different.

Hypothesis 3: There is no significant difference among undergraduate students in 100, 200, 300, 400 and other levels on the perceived effects of computer-based examination (CBE) on essay writing skills of undergraduates in Ambrose Alli University, Ekpoma, Edo State

Table 3. Summary of Perceived effects of computer-based examination (CBE) on essay writing skills of undergraduates in Ambrose Alli University, Ekpoma, Edo State according to their level of Study

\begin{tabular}{lllllll}
\hline & $\begin{array}{l}\text { Sum of } \\
\text { Squares }\end{array}$ & df & $\begin{array}{l}\text { Mean } \\
\text { Square }\end{array}$ & F-ratio & p-value & Remark \\
\hline Between Groups & .207 & 4 & .052 & & & Null hypothesis \\
Within Groups & 99.394 & 531 & .187 & .276 & .894 & retained (p>0.05) \\
\hline Total & 99.601 & 535 & & & & \\
\hline
\end{tabular}

a. Dependent Variable: Students' attitude towards Computer-Based examination (CBE)

b. Predictor: Level of study

Data in Table 4 showed that the F-value of .276 is not statistically significant ( $p>0.05)$. Hence, the null hypothesis is retained. This indicated that there is no significant difference among undergraduate students in 100, 200, 300, 400 and other levels on the perceived effects of computer-based examination (CBE) on essay writing skills of undergraduates in Ambrose Alli University, Ekpoma, Edo State. This also indicates that undergraduate students' perception on the effects of computer-based examination (CBE) on essay writing skills do not differ according to their level of Study.

The result showed that there is a significant difference between male and female undergraduate students in their attitude towards Computer-Based examination (CBE) in Ambrose Alli University, Ekpoma, Edo State. This result could be as a result of students' exposure to modern ICT gadgets such as internet services, computer devices, and personal digital assistances (PDAs) which have made them familiar with various internet skills such as surfing, downloading, and uploading among other. Furthermore, the proliferation of social media and internet services has risen to a point many students have access to do many times from their smartphones, laptops and personal computers. Hence, they have favourable predisposition towards writing examinations.

The agrees with that of Loyd and Gressard (2015) who found out positive, the attitude of students and their teachers toward computers are widely recognized as a necessary condition for effective use of CBT in the classroom. The result corroborates that of Desai, Richards and Eddy (2000) who reported that "the CBT group's overall end-of-training and onemonth-after-training performances were significantly better than CBT subject's performances.

The result is in line with that of Merchant, Kreie and Cronan (2001) who stated that subjects' performance scores in multimedia CBT group were significantly less than those in lecture and handout groups and the multimedia CBT group was less satisfied with their instructional method in Turkish. The result agrees with that of Gurbuz, Yildirim and Ozden (2001) who found out that neither the on-line nor the traditional computer literacy course significantly changed student teachers' attitudes towards computers in Turkish.

The result shows that there is a significant difference between male and female undergraduate students in their attitude towards Computer-Based examination (CBE) in 
Ambrose Alli University, Ekpoma, Edo State. The result agrees with that of Efuwape and Aremu (2013) who reported that there was a significant difference in students' attitude towards computer based examination based on the gender of respondents in Ogun State.

The result disagrees with that of Durojaye and Okon (2016) that gender does not have significant influence on students' views of computer-based testing/examination in Kogi State University, Anyigba, Kogi State, Nigeria. The result is in line with that of Adebowale, Adewale and Oyeniran (2010) who found out that males appear to be more positive in their attitudes toward computers than females. The result disagrees with that of Dammas (2016) who stated that no statistically significant gender differences.

The result shows that there is no significant difference between young and old undergraduate students in their attitude towards Computer-Based examination (CBE) in Ambrose Alli University, Ekpoma, Edo State. This could be due to the globalization, parallelization and digitalization of ICT that has made it convenient for students of all ages to get exposed to computer devices.

Furthermore, the early exposure of students in this globalization age has made computers and ICT gadgets more accessible for students' use irrespective of their parents' economic background, ethnic group or ages. The result from this study disagrees with that of Dammas (2016) who noted that students' age was also found to be a significant predictor of computer based examination in KAU - Saudi Arabia Jeddah.

The result is not in line with that of Oludipe (2012) who noted that computer based examination increased significantly after their participation with respect to their ages in Ogun State, South-west Nigeria. The result does not support that of Zakka (2014) who found that there is a significant relationship between age differences in students' attitude towards $\mathrm{CBE}$ as regards their age in Kaduna State.

The result showed that there is no significant difference among undergraduate students in 100level, 200level, 300level, 400level and other levels in their attitude towards ComputerBased examination (CBE) in Ambrose Alli University, Ekpoma, Edo State. Although, one could have expected that increment in students in their study year could increase their attitude towards CBT and thereby bring about differences in their attitude towards CBT. However, the result has shown that such difference does not exist. This could be due to favourable predisposition towards ICT among many students prior before many of them gained admission into school. Put simply, many of them are already exposed to using computers for many tasks such as chatting, requesting and buying things on the internet. Hence, using Computer-Based examination (CBE) in schools is only a more convenient way and a "win-win" for many.

The result disagrees with that of Adigun, Onihunwa, Irunokhai, Sada and Adesina (2015) who found that there is a significant relationship between levels of study and students' attitude towards computer based examination among Computer Science Student in New Bussa, Borgu Local Government of Niger State. This is not in line with that of Adekunle (2016) who reported that the level of study differences existed in students' attitude towards computer based examination in Federal Capital Territory (FCT), Abuja, Nigeria.

The result disagrees with that of Oludipe (2012) found a significant relationship between junior school students and levels of computer anxiety. The result does not corroborates that of Onihunwa, Irunokhai, Sada and Adesina (2015) found that junior had differing selfefficacy with respect to use of computers and higher computer anxiety than high school students in Federal Capital Territory (FCT), Abuja, Nigeria. The result disagrees with that of Maurer (2001) discovered that 'older school students' reported lower self-efficacy for computer-related training, revealing age related declines for specific efficacies. 


\section{CONCLUSION}

Computer-Based Examination (CBE) is a method of administering tests in which the responses are electronically recorded, assessed, or both. It is commonly available for several admissions tests in developed countries and more recently used by universities as a more convenient way of writing test and examinations. Based on findings, it can be concluded that computer-based examination (CBE) has effect on their essay writing skills as undergraduates in Ambrose Alli University, Ekpoma, Edo State. Hence, it is concluded that undergraduate students of Ambrose Alli University, Ekpoma perceived that computer-based examination (CBE) has effect on their essay writing skills. Female undergraduates of Alli University, Ekpoma, Edo State had higher perception on the effect of CBE on essay writing but their perception of $\mathrm{CBE}$ on essay writing did not differ by age and level of study.

\section{REFERENCES}

Adebowale, O.F. Adewale, I.A. \& Oyeniran, F.M. (2010). Computer interest, approval and confidence of secondary school students in three selected local governments of Lagos State (Nigeria): Implications for global computerization. International Journal of Education and Development using Information and Communication Technology (IJEDICT), 6 (1), 40-52.

Adigun, J., Onihunwa, J. Irunokhai, E., Sada, Y. \& Adesina, O. (2015). Effect of gender on students' academic performance in computer studies in secondary schools in New Bussa, Borgu Local Government of Niger State. Journal of Education and Practice 6(33),1-7.

Adigun, J., Onihunwa, J. Irunokhai, E., Sada, Y. \& Adesina, O. (2015). Effect of gender on students' academic performance in computer studies in secondary schools in New Bussa, Borgu Local Government of Niger State. Journal of Education and Practice 6(33),1-7.

Agah, J.J. Ogbeche, A. U. \& Okorie, E. U. (2016). Computer anxiety, operation skills and attitude as correlates of students' preparedness for computer based assessment. International Journal of Education and Research, 4(2), 71-84.

Agah, J.J., Ogbeche, A.T. \& Okorie, E.U. (2016). Computer anxiety, operation skills and attitude as correlates of students' preparedness for computer based assessment. International Journal of Education and Research. 4 (2),71-81

Bodmann, S. M. and Robinson, D. H. (2004). Speed and Performance Differences among Computer-Based and Paper-Pencil Tests. Journal of Educational Computing Research, 31(1), $51-60$.

Dammas, A.H. (2016). Investigate students' attitudes toward computer based test (CBT) at Chemistry Course. Archives of Business Research. 4(6),58-71

Durojaye D. S. \& Okon, E.O. (2016). students' perception of computer-based test in Kogi State University: a quantitative approach. International Journal of Management, IT and Engineering. 5(12), 1-18.

Kumar, R. (2006). Convergence of ICT and Education. World Academy of Science, Engineering and Technology 40 2016. Retrieved on November 25 2017, from: http://www.waset.org/journals/waset/v40/v40-95.pdf

Loyd, H. \& Gressard C. P. (2015). "Reliability and Factorial Validity of Computer Attitude Scales". Educational \& Psychological Measurement, 44, 501-505.

Mubashrah, J., Tariq, R.H. \& Shami, P.A. (2012). Computer-based vs paper-based examinations: perceptions of university teachers. The Turkish online Journal of Educational Technology (TOJET), 11(4), 371-381. 
Olawale, \& Shafi'i M. A. (2010), E- Exams System for Nigerian Universities with Emphasis on Security and Result Integrity. Proceedings of The Seventh International Conference on e-learning for knowledge-Based Society, Thailand.

Oludipe, D. I. (2012). Gender difference in Nigerian junior secondary students' computer based test in Basic Science. Journal of Educational and Social Research.2 (1), 93-99

Sanni, A. A. \& Mohammad, M. F. (2015). Computer based testing (CBT): an assessment of student perception of JAMB UTME in Nigeria. Computing, Information Systems, Development Informatics \& Allied Research Journal. 6(2), 13-28.

Saparniene, D., Merkys, G., \& Saparnis, G. (2002). Students' computer literacy and social environment in the context of the society with limited resources. In Proceedings of the International Conference of the International Association for Reseach on Textbooks and Educational Media: Learning and Educational Media (Vol. 3, pp. 126-136).

Zakka, J. (2014). Innovative strategies for curbing examination malpractices in public examinations in Nigeria. An unpublished thesis submitted to University of Nigeria, Nsukka. 